\title{
Salinity-induced changes in the rhizosphere microbiome improve salt tolerance of Hibiscus hamabo
}

\author{
Yongge Yuan • Caroline Brunel • Mark van Kleunen • \\ Junmin Li • Zexin Jin
}

\begin{abstract}
Aims We aimed to assess whether soil salinity changes the microbial community in the rhizosphere of Hibiscus hamabo, and whether these changes in the microbiome feedback on the growth of $H$. hamabo.

Methods To test effects of salinity on the rhizosphere microbiome, we first did a greenhouse experiment in which $H$. hamabo was grown in pots with a sand-soil mixture at different salt concentrations $(0,15,40$ and $90 \mathrm{mM} \mathrm{NaCl}$ ). Then in another two experiments, we tested effects of the rhizosphere microbiomes on performance of $H$. hamabo plants by sowing and growing them in pots with a peat-sand-vermiculite mixture inoculated with either soil or root fragments collected from
\end{abstract}

Y. Yuan · C. Brunel · M. van Kleunen · J. Li $(\bowtie) \cdot$

Z. Jin $(\bowtie)$

Zhejiang Provincial Key Laboratory of Plant Evolutionary

Ecology and Conservation, Taizhou University, Taizhou 318000,

China

e-mail: lijmtzc@126.com

e-mail: jzx@tzc.edu.cn

Y. Yuan · C. Brunel · M. van Kleunen · J. Li

School of Advanced Study, Taizhou University, Taizhou 318000 , China

M. van Kleunen

Ecology, Department of Biology, University of Konstanz,

Universitätsstrasse 10, D-78457 Constance, Germany the different salinity treatments $(0,40$ and $90 \mathrm{mM} \mathrm{NaCl})$ of the first experiment and crossed with a salinity treatment $(0,40$ and $90 \mathrm{mM} \mathrm{NaCl})$.

Results The bacterial rhizosphere community of $H$. hamabo was less affected by soil salinities than the fungal community was. Germination and biomass of H. hamabo were highest at a salinity of $40 \mathrm{mM} \mathrm{NaCl}$, and higher in the presence than in the absence of microbial inoculums. Moreover, H. hamabo performed best when the microbial inocula came from the same salinity level, particularly at a salinity of $40 \mathrm{mM} \mathrm{NaCl}$.

Conclusions Our study provides evidence that salinityinduced changes in rhizosphere microbial communities tend to promote germination and growth of H. hamabo at the respective salinities.

Keywords Hibiscus hamabo $\cdot$ Local adaptation · Plant tolerance $\cdot$ Salt stress $\cdot$ Soil microbial community

\section{Introduction}

Organisms are continuously exposed to environmental stress factors, such as high temperatures, drought, pollution and salinity. Sessile organisms, such as plants, cannot move away from such stresses, and rely strongly on mechanisms that allow them to cope with environmental stress. Some of these mechanisms, such as phenotypic plasticity (Nicotra et al. 2010), local adaptation (Oduor et al. 2016), parental carry-over effects (e.g. though differences in seed provisioning; Roach and Wulff 1987) and epigenetics (Bossdorf et al. 2008) are 
relatively well-studied or have received increased attention lately. However, the role of changes in a plant's microbiome in coping with stress have so far received far less attention (Lau and Lennon 2012).

About $7 \%$ of the Earth's land surface consists of saline soils (Ruiz-Lozano et al. 2012). This percentage is increasing, as a consequence of e.g. climate-change driven increases in evaporation, sea-water infiltration, improper irrigation and excessive use of chemical products, and as a consequence salinization has become a growing ecological problem in many parts of the world (Giri et al. 2003; Al-Karaki 2006; Ruiz-Lozano et al. 2012). Unraveling ecological mechanisms underlying salt tolerance in plants, halophytes in particular, will help achieve a more efficient use and amelioration of saline soils ( $\mathrm{Li}$ et al. 2012).

High salinity adversely affects plant growth and development by causing a series of molecular, biochemical, physiological and morphological changes (Evelin et al. 2009; Aroca et al. 2013). This is because salinity alters water relations of plant' tissues, and causes nutrient imbalance and toxicity due to excess amounts of $\mathrm{Na}^{+}$ and $\mathrm{Cl}^{-}$ions in the cells (Tester and Davenport 2003). Salinity may not only affect plants directly but may also affect the soil microbes they interact with. Indeed, a number of studies have shown that salinity can affect the activity, biomass and structure of microbial communities (Yan et al. 2015). For instance, microbial biomass was shown to be reduced by high salinity, because osmotic stress resulted in water efflux from the microbial cells (Yuan et al. 2007). The effects of salinity on microbes are, however, not always consistent. Some studies found that salt stress has detrimental effects on arbuscular mycorrhizal fungi (AMF) by inhibiting spore germination, hyphal growth, colonization of plants and formation of an effective symbiosis (Juniper and Abbott 2006; Giri et al. 2007; Sheng et al. 2008), whereas in other studies salinity enhanced AMF sporulation and colonization (Jahromi et al. 2008). This indicates that some microbes might suffer while others might benefit from salinity. Indeed, salt stress can shape the composition of soil microbial communities (Walsh et al. 2005; Mohamed and Martiny 2011; Rath and Rousk 2015). So far, however, despite the fact that effects of soil salinity on soil microbes have been reported in numerous studies, few studies have tested whether the effects of salinity on soil microbes helps to alleviate salt stress on plants.
It has been shown that under salt stress plants grow better in the presence than in the absence of soil microbes (Patel et al. 2017; Sarkar et al. 2018). Soil microbes, and particularly AMF, could help plants to maintain a high $\mathrm{K} / \mathrm{Na}$ ratio under salt stress conditions to prevent plants from injury (Porcel et al. 2012). Some of these effects may also be mediated by phytohormones. For instance, Li et al. (2017) found that canola (Brassica napus) plants inoculated with the halotolerant bacterium Enterobacter cloacae HSNJ4 became more salt tolerant, and that this was associated with increases in endogenous indole-3-acetic acid (IAA) concentrations. Furthermore, Lastochkina et al. (2017) found that the endophytic bacterium Bacillus subtilis enhanced the contents of salicylic acid and water in leaves, and reduced the contents of proline and malondialdehyde in salt-resistant wheat (Triticum aestivum). So, if salinity promotes the microbes that benefit growth of plants in saline soils, this would provide an ecological salttolerance mechanism of plants.

The idea that particularly those microbial communities that have previously experienced a stress condition confer tolerance to that stress for plants is called the "habitat-adapted symbiosis" hypothesis (Rodriguez et al. 2008). For example, geothermal endophytes confer heat tolerance but do not confer salt tolerance, whereas coastal endophytes confer salt tolerance but do not confer heat tolerance (Rodriguez et al. 2008). In other words, the microbial community that arose under a certain environmental condition is more likely to benefit plants that grow under that specific environmental condition compared to a microbial community that assembled under different environmental conditions. This might result in a pattern of apparent local adaptation in plants, as demonstrated for Brassica rapa in response to drought (Lau and Lennon 2012). However, it is not known whether the past salt-conditions experienced by a microbial community affects the tolerance it confers to plants.

Hibiscus hamabo Siebold \& Zuccarini (Malvaceae) is an endangered deciduous tree or shrub native to Asia (Zhou et al. 2013), where its main distribution is on coastal sands in China, Japan and Korea (Li et al. 2012). Hibiscus hamabo is a halophyte and grows well in habitats with $\mathrm{NaCl}$ concentrations ranging from 1.1 to $1.5 \%$ (Li et al. 2012). Therefore, H. hamabo is currently considered as one of the best afforestation species for amelioration of soil salinization in coastal areas of eastern China. So far, only few studies have investigated the 
mechanism of salt tolerance in H. hamabo, and the ones that did focused on changes in physiological properties in response to different salinity levels ( $\mathrm{Li}$ et al. 2012; Zhou et al. 2013). However, no study has yet tested the role of soil microbes in salt tolerance of H. hamabo.

In this study, we investigated how interactions between soil salinity and microbes affect salt tolerance of $H$. hamabo. We first examined changes in microbial communities in the rhizosphere of $H$. hamabo plants grown at four different salt concentrations (watering with $0,15,40$ and $90 \mathrm{mM} \mathrm{NaCl}$ ). Then we tested the effects of the microbial communities collected from these different salinity treatments, either as soil inoculum or root inoculum, on seed germination and sapling growth of $H$. hamabo at three of the salt concentrations $(0,40$ and $90 \mathrm{mM} \mathrm{NaCl})$. We hypothesized that the rhizosphere microbial communities would be changed by the salinity treatment in such a way that they promote germination and growth (i.e. increase salt tolerance) of H. hamabo.

\section{Materials and methods}

Effects of salinity on growth of Hibiscus hamabo and on its rhizosphere microbial community

To test the effect of soil salinity on growth of H. hamabo and on its rhizosphere microbial community, we grew 10 replicate plants at each of four levels of salinity $(0$, 15,40 and $90 \mathrm{mM} \mathrm{NaCl}$ ). There were 40 pots in total. To be able to create a gradient from low to high salinities, we used a non-saline field soil as base substrate. The soil was a sandy loam with a $\mathrm{pH}$ of 7.35 (2.5:1, $\mathrm{KCl}$ aqueous solution: soil), $13.91 \mathrm{~g} \mathrm{~kg}^{-1}$ organic matter, $0.9 \mathrm{~g} \mathrm{~kg}^{-1}$ total nitrogen, $0.17 \mathrm{~g} \mathrm{~kg}^{-1}$ total phosphorus, and $16.3 \mathrm{mg} \mathrm{kg}^{-1}$ extractable K. Prior to use, the soil was air dried, passed through a sieve with a mesh width of $5 \mathrm{~mm}$, and mixed with sand (1:1 by weight).

Seeds of H. hamabo, collected in a population in Zhoushan (Zhejiang province, China), were surface sterilized in a $0.5 \% \mathrm{NaClO}$ solution for $10 \mathrm{~min}$, washed three times with sterile water, and germinated on sterilized moist filter paper in petri dishes. On 1st September 2017, sixteen days after sowing, we transplanted three seedlings into each pot (10 cm upper diameter, $12 \mathrm{~cm}$ height) filled with $630 \mathrm{~g}$ of the soil substrate. After 1 week, the plants were thinned to one seedling per pot.
The experiment was conducted in a non-heated greenhouse with $50 \%$ of ambient light, and with an air temperature ranging from -1 to $30^{\circ} \mathrm{C}$ during the period of the experiment. Plants were watered daily to keep soil moisture at $70-90 \%$ of water-holding capacity. No additional nutrients were added. Plants were allowed to acclimatize for 10 weeks before the start of the salinity treatment. Then, four levels of saline solution $(0,15,40$ and $90 \mathrm{mM} \mathrm{NaCl}$ ) were added to the corresponding pots for a period of 30 days $(50 \mathrm{ml}$ per 3 days; a total of $500 \mathrm{ml}$ was added to each pot). The electrical conductivity values of the different $\mathrm{NaCl}$ solutions ranged from 291 to $680 \mu \mathrm{S} \mathrm{cm}^{-1}$ (Table S1 in Supplementary material), which is within the range of values reported for field soils where H. hamabo grows (c. 200 to $2000 \mu \mathrm{S}$ $\mathrm{cm}^{-1}$; Li 2008; Wang 2010). The plants were harvested 350 days after transplantation.

Plants were separated into shoots and roots by cutting the shoot at a distance of $2 \mathrm{~cm}$ above the soil surface (Göransson et al. 2016). Shoot biomass was oven-dried at $65^{\circ} \mathrm{C}$ for $48 \mathrm{~h}$. The fresh roots were weighed immediately. Then half of each root sample by fresh weight was oven-dried, and the dry biomass of the total root system was calculated. The root weight ratio (RWR) was calculated as root biomass/total biomass. The remaining half of each root sample was used for quantification of AMF colonization (see Fig. S1) using a microscope $(\times 20$ magnification $)$ and the gridline intersection method (Giovannetti and Mosse 1980) with 200 transects per replicate.

For analysis of the microbial community, using $16 \mathrm{~S}$ and ITS amplicon sequencing, we collected rhizosphere soil from three randomly chosen plants per salinity level. The rhizosphere soil samples were collected by excavating the entire root system, removing the bulk soil, and then shaking the roots gently to collect rhizosphere soil. DNA was extracted from the rhizosphere samples using a soil DNA Extraction Kit (Tiangen Biotech, Beijing, China). Then the bacterial 16S rRNA gene and the fungal internal transcribed spacer (ITS) region were amplified using the primer pair $341 \mathrm{~F} /$ 806R (5'-CCTACGGGAGGCAGCAG-3'/5'-GGA CTACHVGGGTWTCTAAT-3') (Takahashi et al. 2014) and ITS1F/ITS2R (5'-GGA AGTAAAAG TCGTAACAAGG-3'/5'-GCTGCGTTCTTCAT CGATGC-3') (Buee et al. 2009) along with the Illumina-adaptor sequence and barcode sequences. The sequencing library was prepared by Y-adapter ligation, self-ligation adapter elimination and PCR amplification. 
Sequencing was performed on an Illumina MiSeq platform (San Diego, CA, USA). The raw sequences were submitted to the National Center for Biotechnology Information (NCBI) database under the bioproject accession number PRJNA515471. The QIIME (Quantitative Insights Into Microbial Ecology) toolkit (Caporaso et al. 2010), and USEARCH and UPARSE software (Edgar 2013) were used to process the raw highthroughput sequencing data. Barcodes and the standard primer sets were excluded. Sequences below the quality score of 20 and with fewer than 200 bp were also excluded (Lin et al. 2012). All sequences were clustered into operational taxonomic units (OTUs) with a 97\%identity threshold. Arbuscular mycorrhizal fungi (AMF) were identified using FUNGuild (Nguyen et al. 2016).

To identify differences in bacterial and fungal community composition, we used non-metric multidimensional scaling (NMDS) ordination plots based on the unweighted Unifrac distance matrix of OTUs. To test whether the bacterial and fungal community composition differed significantly among the different salinitytreatment levels, we used ANOSIM. These analyses were performed in $\mathrm{R}$ (version 3.1.2; $\mathrm{R}$ Core Team 2014; http://www.r-project.org/) using the "vegan" package (Oksanen et al. 2011).

Effects of rhizosphere-soil inoculum and salinity on Hibiscus hamabo

To test whether the rhizosphere microbial communities that developed under different salinities affect seed germination and sapling growth of $H$. hamabo grown at different salinity levels, we did a soil inoculation experiment. We used rhizosphere soil of $H$. hamabo grown at 0,40 or $90 \mathrm{mM} \mathrm{NaCl}$ in the first experiment as soil inocula. The rhizosphere soil was collected by carefully shaking off the soil that was still adhering to the roots after they had been excavated from the bulk soil. We pooled and mixed similar volumes of rhizosphere soil from each of the 10 pots in a salinity treatment, and used this as inoculum. For the experiment, we filled pots (10 $\mathrm{cm}$ upper diameter, $12 \mathrm{~cm}$ height) with a sterilized substrate consisting of a mixture of peat, sand and vermiculite $(6: 3: 1 \quad v / v / v)$. Sterilization was done by autoclaving for $2 \mathrm{~h}$ at $121^{\circ} \mathrm{C}$. The sterilized soil in each pot was inoculated with the collected rhizosphere soils from one of the three salinity treatments. The inoculum and substrate were mixed in a ratio of 1:20 $(\mathrm{v} / \mathrm{v})$ (Lau and Lennon 2011). As controls for adding inoculum soil, we also inoculated pots with autoclaved rhizosphere soil.

This experiment had three salinity levels $(0,40$ and $90 \mathrm{mM} \mathrm{NaCl}$ ) crossed with three microbe-inoculum origins (rhizosphere soil samples collected from the 0 , 40 and $90 \mathrm{mM}$ salinity treatments of the first experiment), as well as two sterilization treatments (inoculum sterilized or not), each with 8 replicates (totaling $3 \times 3 \times$ $2 \times 8=144$ pots). Soil salinity treatments and the greenhouse were the same as in the first experiment. On 24th August 2018, 10 seeds of $H$. hamabo were sown in each pot. The numbers of successfully germinated seeds in each pot were recorded for 15 days. Germination rate (i.e. the percentage of germinated seeds) was calculated by dividing the number of germinated seeds by the number of sown seeds and multiplying this ratio by 100 .

Sixteen days after sowing, the number of seedlings in each pot was thinned to one. Plants were watered daily to keep soil moisture at $70-90 \%$ of water-holding capacity. Two months after the start of the experiment, the plants were harvested and oven dried to constant mass for the measurement of dry biomass.

Effects of root-segment inoculum and salinity on Hibiscus hamabo

In addition to the rhizosphere-soil-inoculation experiment, we also did a similar experiment using as inoculum root segments, which may in addition to rhizosphere microbes also contain endosphere microbes. The root segments of $H$. hamabo were collected from the $H$. hamabo plants grown at different salinities $(0,40$ and $90 \mathrm{mM} \mathrm{NaCl}$ ) in the first experiment (on a mixture of soil and sand). Eight out of ten plants from each salinity level were randomly selected, and we cut their fine roots $(<2 \mathrm{~mm}$ in diameter) into segments with a length of $1 \mathrm{~cm}$. We washed the root segments with water, and then randomly selected 10 segments for inoculation in the center of each pot $(10 \mathrm{~cm}$ upper diameter, $12 \mathrm{~cm}$ height), filled with a sterilized (i.e. autoclaved for $2 \mathrm{~h}$ at $121{ }^{\circ} \mathrm{C}$ ) mixture of peat, sand and vermiculite $(6: 3: 1 \mathrm{v} / \mathrm{v} / \mathrm{v})$.

One seedling of $H$. hamabo was transplanted into each pot. The experiment had three salinity levels $(0$, 40 and $90 \mathrm{mM} \mathrm{NaCl}$ ) and three root inoculum origins (root-inoculum samples collected from the 0, 40 and $90 \mathrm{mM}$ salinity treatments of the first experiment), each with 8 replicates. As a control, we also had 8 pots without root inoculum, resulting in a total of 96 pots. 
The salinity treatments were applied in the same way as the other experiments, and this experiment was done in the same greenhouse. Plants were watered daily to keep soil moisture at 70-90\% of water-holding capacity. Two months after the start of the experiment, the plants were harvested and oven dried to constant mass for the measurement of dry biomass.

\section{Data analysis}

In the first experiment, without rhizosphere-soil and root-segment inocula, the effects of salt concentrations on biomass, RWR, AMF OTUs, colonization rates, and indices of bacterial and fungal diversity (Shannon index, Simpson index and OTU richness) were analyzed with one-way ANOVAs using the general linear model procedure. In the experiment with rhizosphere-soil inocula, the effects of salinity treatment, soil-inoculum origin and sterilization, as well as their interactions, on germination and total biomass of $H$. hamabo were analyzed with three-way ANOVAs. In the experiment with root-segment inocula, the effects of the salinity treatment and root-inoculum origin on total biomass of $H$. hamabo were analyzed with a twoway ANOVA.

In addition, to test whether the rhizosphere-soil or root-segment inoculum promoted performance of $H$. hamabo when the current salinity treatment level and the inoculum origin matched, we also reran the ANOVAs after replacing soil or root inoculum origin with a "local-foreign" factor. The local-foreign test is frequently used in studies on local adaptation (Kawecki and Ebert 2004, also see Oduor et al. 2016). A better performance of individuals from the local population (the current salinity treatment level and the inoculum origin matched) than from the foreign population (the current salinity level and the inoculum origin differed) would indicate local adaptation (Kawecki and Ebert 2004). Differences between treatments were compared using LSD at the 5\% significance level. All the analyses were performed using SPSS (V.17.0). The Kolmogorov-Smirnov and the Levene test showed that the residuals of the models did not significantly deviate from normality and homogeneity of variance, respectively.

\section{Results}

Effect of salinity on plant biomass and RWR

The salinity treatment (i.e. $\mathrm{NaCl}$ concentrations) significantly affected the total biomass of H. hamabo $(p<0.001$; Fig. 1). Total biomass under $15 \mathrm{mM}$ and $40 \mathrm{mM} \mathrm{NaCl}$ was circa $10 \%$ higher than under $0 \mathrm{mM}$, and circa $77 \%$ higher than under $90 \mathrm{mM} \mathrm{NaCl}$ (Fig. 1a). There was no significant difference in total biomass and RWR between plants in the $15 \mathrm{mM}$ and $40 \mathrm{mM}$ salinity treatments. The overall effect of the salinity treatment on RWR of $H$. hamabo was marginally non-significant $(p=0.058)$ (Fig. 1b).

Effect of salinity on rhizosphere microbial communities

The numbers of sequences and bases, and average length of each sample for sequencing are shown in Table S2. The analysis of the rhizosphere bacteria detected a total of 5058 OTUs, which were dominated by the phyla Protebacteria $(\sim 28 \%)$, Firmicutes $(\sim 28 \%)$ and Acidobacteria ( $\sim 9 \%)$, and by the genera Bacillus $(\sim 13 \%)$ and Lactococcus ( 11\%) (Figs. S2 and S4). Although there was a slight trend that bacterial OTU richness and the Shannon and Simpson indices decreased with increasing salinity (Fig. 2a, b; Fig. S6a), these effects were not significant $(p>0.05$; Table S3). The NMDS plot revealed a weak separation in the composition of the bacterial communities among the four salinity treatments (Fig. 2c), and these differences were marginally non-significant $(p=0.065)$ in the ANOSIM analysis.

The analysis of the rhizosphere fungi detected a total of 879 OTUs, and these were dominated by Ascomycota $(\sim 69 \%)$, Mucoromycota $(\sim 8 \%)$ and Basidiomycota $(\sim 3 \%)$, and by the genera Humicola $(\sim 15 \%)$, Thielavia $(\sim 12 \%)$ and Paraglomus ( $\sim 6 \%)$ (Figs. S3 and S5). Whereas there was a trend that fungal OTU richness decreased with increasing salinity, the Shannon and Simpson indices both showed opposite trends (Fig. $2 d$, e; Fig. S6b). Although the overall effects of the salinity treatments on OTU richness and the Shannon and Simpson indices were not significant $(p>0.05$; Table S3), LDS tests revealed significant differences between the $0 \mathrm{mM}$ and $90 \mathrm{mM} \mathrm{NaCl}$ treatments (Fig. 2d, e; Fig. S6b). The NMDS plot revealed a separation in the composition of the fungal communities among the four salinity treatments (Fig. 2f), and these differences 

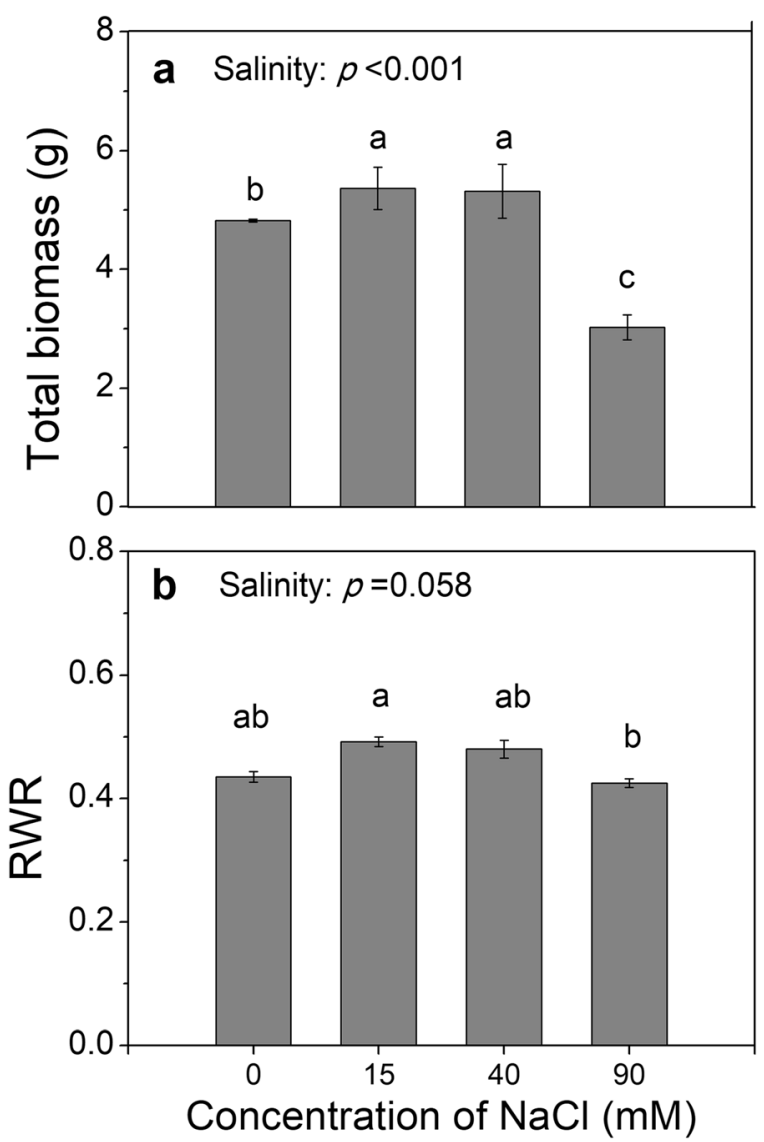

Fig. 1 Effect of soil salinity treatments (watering with 0, 15, 40 or $90 \mathrm{mM} \mathrm{NaCl}$ solutions) on total biomass (a) and root weight ratio (RWR) (b) of Hibiscus hamabo. Different letters above the bars indicate significant differences $(P<0.05)$

were significant $(p=0.026)$ in the ANOSIM analysis. Moreover, the hyphal and vesicular colonization rates of $H$. hamabo roots significantly increased with increasing salinity levels (Fig. 3).

Effects of salinity and soil-inoculum origin on germination and biomass

Salinity had a significant effect on germination of $H$. hamabo seeds, with the highest germination at the intermediate $\mathrm{NaCl}$ concentration of $40 \mathrm{mM}(p<0.001$, Table 1; Fig. 4a). The addition of a live inoculum significantly increased germination rate by $46 \%$ $(p<0.001$, Table 1; Fig. 4a). However, the soilinoculum origin did not significantly affect the germination rate $(p>0.05$, Table 1; Fig. 4a). None of the interactions between salinity, inoculum sterilization and inoculum origin were significant (Table 1).
Although in the subset of pots with live inoculates, germination rates at $40 \mathrm{mM}$ and $90 \mathrm{mM} \mathrm{NaCl}$ were highest when the previous salinity levels of the soil microbes matched the current ones, there was no significant local-foreign effect or salinity $\times$ local-foreign interaction (Table S4).

Salinity had a significant effect on total biomass of $H$. hamabo, with again the highest values at the intermediate $\mathrm{NaCl}$ concenctration of $40 \mathrm{mM}(p<0.001$, Table 1; Fig. 4b). The addition of a live inoculum significantly increased biomass by on average $23 \%$ $(p<0.001$, Table 1; Fig. $4 \mathrm{~b})$, but this effect was stronger at salinities of 0 and $40 \mathrm{mM}$ than at a salinity of $90 \mathrm{mM}$ (significant salinity $\times$ sterilization interaction in Table 1 ; Fig. 4b). Moreover, soil-inoculum origin had a significant effect on total biomass, as overall biomass was highest when the soil inoculum came from a salinity of $40 \mathrm{mM} \mathrm{NaCl}$ (Table 1; Fig. 4b). In the subset of pots with live inoculates, the beneficial effect of the $40 \mathrm{mM}$ soil-inoculum was strongest at a current salinity of $40 \mathrm{mM}$, and therefore, the local-foreign effect was borderline significant ( $p=0.050$, Table S4).

Effects of salinity and root-segment inoculum origin on biomass

In the root-inoculum experiment, salinity had a significant effect on total biomass of H. hamabo, with again the highest values at the intermediate $\mathrm{NaCl}$ concenctration of $40 \mathrm{mM}$ ( $p<0.001$, Table 2; Fig. 5). Root-inoculum addition (i.e. control without root inoculum vs the treatments with root inoculum) significantly increased biomass $(p<0.001$, Table 2$)$, but particularly so at the salinities of 0 and $40 \mathrm{mM}$ (significant salinity $\times$ root-inoculum addition interaction in Table 2; Fig. 5). For the subset of pots with root inoculum, the origin of the root inoculum significantly affected total biomass $(p<0.001$, Table 3$)$. The interactions between salinity and root-inoculum origin were significant (Table 3 ). When we analysed this subset of pots with the factor local-foreign instead of root-inoculum origin, the effect of local-foreign and its interaction with salinity were both significant (Table S5). At a current salinity of $0 \mathrm{mM} \mathrm{NaCl}$, total biomass was highest when the root inoculum also came from a salinity of $0 \mathrm{mM}$ or $40 \mathrm{mM}$, at a current salinity of $40 \mathrm{mM} \mathrm{NaCl}$, biomass was highest when the root inoculum also came from a salinity of $40 \mathrm{mM}$, whereas at a current salinity of $90 \mathrm{mM}$ $\mathrm{NaCl}$, the root-inoculum origin did not matter (Fig. 5). 

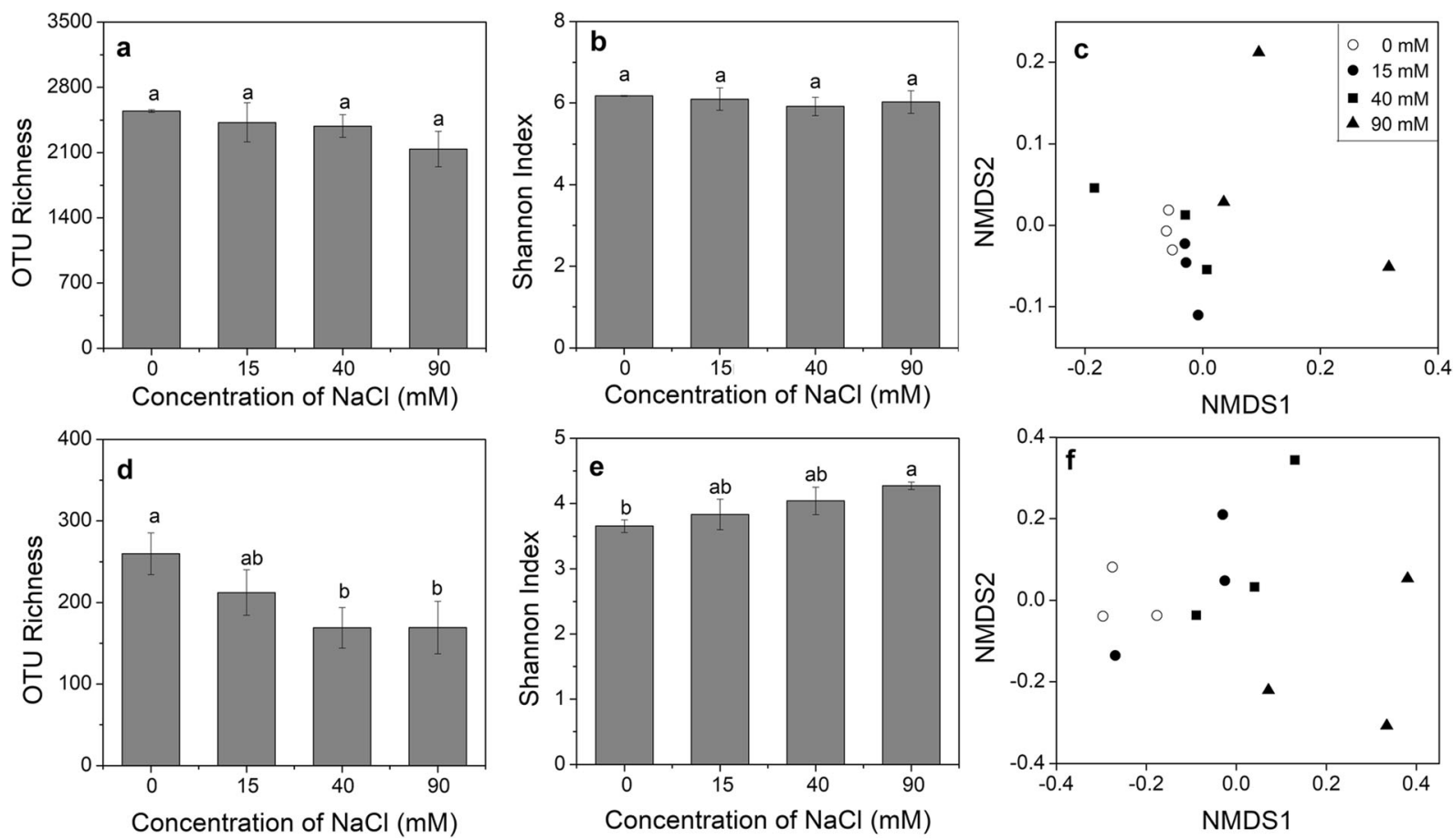

Fig. 2 Effect of soil salinity treatments (watering with $0,15,40$ or $90 \mathrm{mM} \mathrm{NaCl}$ solutions) on OTU richness (a, d), the Shannon diversity index $(\mathbf{b}, \mathbf{e})$ and composition $(\mathbf{c}, \mathbf{f})$ of rhizosphere bacterial $(\mathbf{a}, \mathbf{b}, \mathbf{c})$ and fungal $(\mathbf{d}, \mathbf{e}, \mathbf{f})$ communities of Hibiscus hamabo.

\section{Discussion}

We tested the hypothesis that the rhizosphere microbial community is changed by salinity in such a way that the microbial community promotes germination and growth (i.e. increase salt tolerance) of H. hamabo. We found that while the bacterial rhizosphere community was only marginally affected by the salinity level, communities of rhizosphere soil fungi and root colonization by AM Fungi of $H$. hamabo changed with salinity. We found that germination and growth of $H$. hamabo were highest at the intermediate salinity level, and higher in the presence than in the absence of microbial inoculates. Moreover, there was a trend that $H$. hamabo performed best when the microbial inoculate came from the same salinity level, particulary at the intermediate salinity level. So, H. hamabo shows tolerance to salinity, at least to intermediate levels, and this tolerance is promoted by local rhizosphere microbes.

The three experiments that we did showed that soil salinity had a direct effect on the performance of $H$. hamabo. Both seed germination and sapling growth were higher at the intermediate salinity level $(40 \mathrm{mM})$
The differences in composition of the communities are shown as Nonmetric Multidimensional Scaling plots (c, f). Different lowercase letters above the bars indicate significant differences $(p<0.05)$

than at the $0 \mathrm{mM}$ level, but decreased again at the highest salinity $(90 \mathrm{mM})$. This shows that H. hamabo is not only salt tolerant but actually prefers intermediately saline over non-saline soils. This is in line with the observation that $H$. hamabo grows well in habitats with $\mathrm{NaCl}$ concentrations ranging from 1.1 to $1.5 \%$ (Yang et al. 2008; Li et al. 2012). However, we also showed that when salinity reached a certain level, it started to become stressful to the plants as it reduced both germination and growth. As high salinity reduces the water potential of the soil, it becomes more difficult for the plant to take up water. A common response to drought stress is that plants invest more biomass into roots (Bloom et al. 1985). Indeed, we found that the RWR of $H$. hamabo tended to increase with increasing salinity. However, at the highest salinity, the RWR decreased again, which is another indication that the salinity level became too stressful.

Salinity affected the soil microbial communities. However, the fungal communities showed stronger responses than the bacterial communities (Fig. 2), which suggests that fungi are more sensitive to salinity than bacteria. These results are in line with several other 

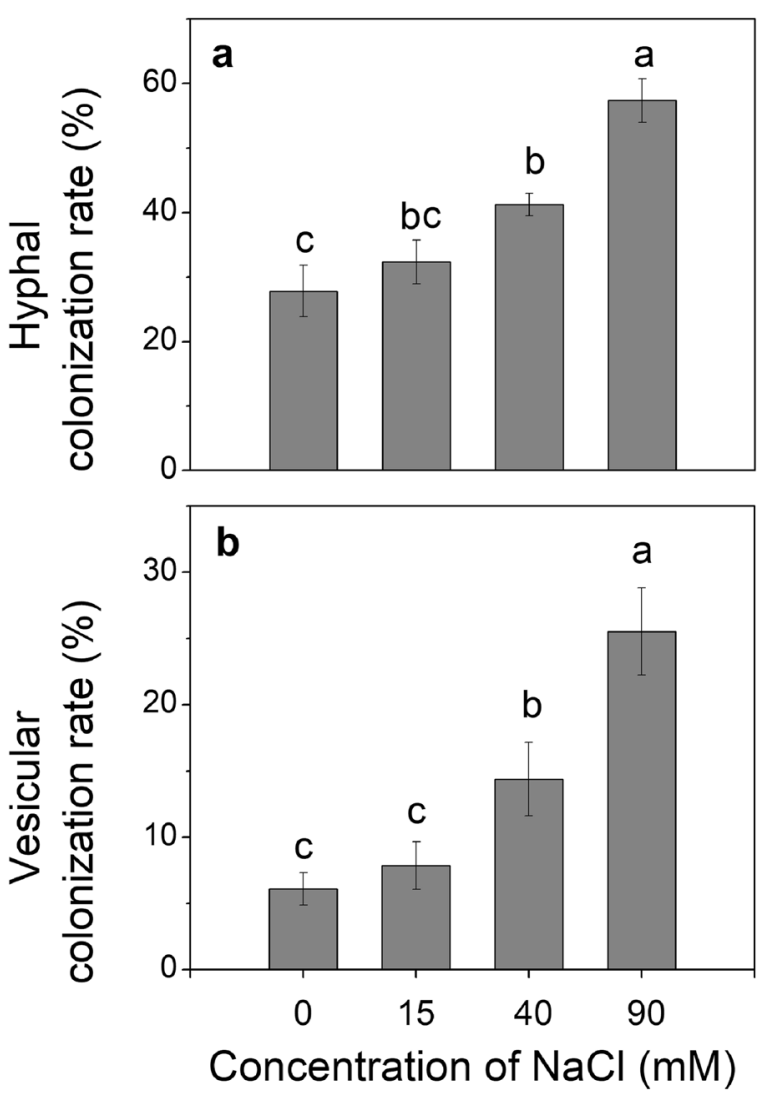

Fig. 3 Arbuscular mycorrhizal fungi (AMF) hyphal colonization rate (a) and vesicular colonization rate (b) of Hibiscus hamabo at different soil salinity treatments (watering with $0,15,40$ or $90 \mathrm{mM}$ $\mathrm{NaCl}$ solutions). Different letters above the bars indicate significant differences $(P<0.05)$ studies demonstrating that bacteria tend to be more tolerant to salt stress (Pankhurst et al. 2001; Sardinha et al. 2003; Yan et al. 2015). Although bacterial diversity indexes were not strongly affected by the salinity levels, there was a reduction, albeit not significant, in OTU richness and a weak, marginally non-significant, distinction in the composition of the bacterial community between the $90 \mathrm{mM} \mathrm{NaCl}$ treatment and the other salinity treatments (Fig. 2c). This could suggest that bacterial communities were more sensitive to the high salinity treatment $(90 \mathrm{mM})$ than to the lower ones $(0$ and $40 \mathrm{mM}$ ). Interestingly, although at $90 \mathrm{mM} \mathrm{NaCl}$ the fungal OTU richness was significantly lower than at $0 \mathrm{mM} \mathrm{NaCl}$, the Shannon and Simpson diversity indices for fungi were significantly higher than at $0 \mathrm{mM} \mathrm{NaCl}$ (Figs. 2d, e and S6b). These opposing results suggest that the salinity treatment might be particularly detrimental to very abundant or very rare fungal OTUs from the non-saline soil, resulting in a higher evenness. Indeed when we calculated Pielou's evenness, the values increased significantly with increasing salinity (Fig. S6d).

Previous observational studies have shown that taxonomic structure of bacterial and fungal communities changes along salinity gradients in the field (Andronov et al. 2012). Here, we showed experimentally that the composition of the microbial community in our study changed with salinity (Fig. 2c, f). Our results are in line

Table 1 Results of three-way ANOVAs testing the main effects and interactions of salt concentration (SC), inoculum sterilization (IS) and microbe-inoculum origin (MI) on seed germination rate and total biomass of Hibiscus hamabo

\begin{tabular}{|c|c|c|c|c|}
\hline & Factors & d.f. & $F$ value & $p$ value \\
\hline \multirow[t]{7}{*}{ Seed germination rate } & Salt concentration (SC) & 2 & 15.543 & $<0.001 *$ \\
\hline & Inoculum sterilization (IS) & 1 & 24.273 & $<0.001 *$ \\
\hline & Microbe-inoculum origin (MI) & 2 & 2.403 & 0.095 \\
\hline & $\mathrm{SC} \times \mathrm{IS}$ & 2 & 0.686 & 0.505 \\
\hline & $\mathrm{SC} \times \mathrm{MI}$ & 4 & 0.503 & 0.734 \\
\hline & $\mathrm{IS} \times \mathrm{MI}$ & 2 & 2.554 & 0.082 \\
\hline & $\mathrm{SC} \times \mathrm{IS} \times \mathrm{MI}$ & 4 & 0.305 & 0.874 \\
\hline \multirow[t]{7}{*}{ Total biomass } & Salt concentration (SC) & 2 & 200.110 & $<0.001 *$ \\
\hline & Inoculum sterilization (IS) & 1 & 80.278 & $<0.001^{*}$ \\
\hline & Microbe-inoculum origin (MI) & 2 & 8.098 & $<0.001 *$ \\
\hline & $\mathrm{SC} \times \mathrm{IS}$ & 2 & 3.288 & $0.041 *$ \\
\hline & $\mathrm{SC} \times \mathrm{MI}$ & 4 & 1.073 & 0.373 \\
\hline & $\mathrm{IS} \times \mathrm{MI}$ & 2 & 0.484 & 0.617 \\
\hline & $\mathrm{SC} \times \mathrm{IS} \times \mathrm{MI}$ & 4 & 1.133 & 0.344 \\
\hline
\end{tabular}



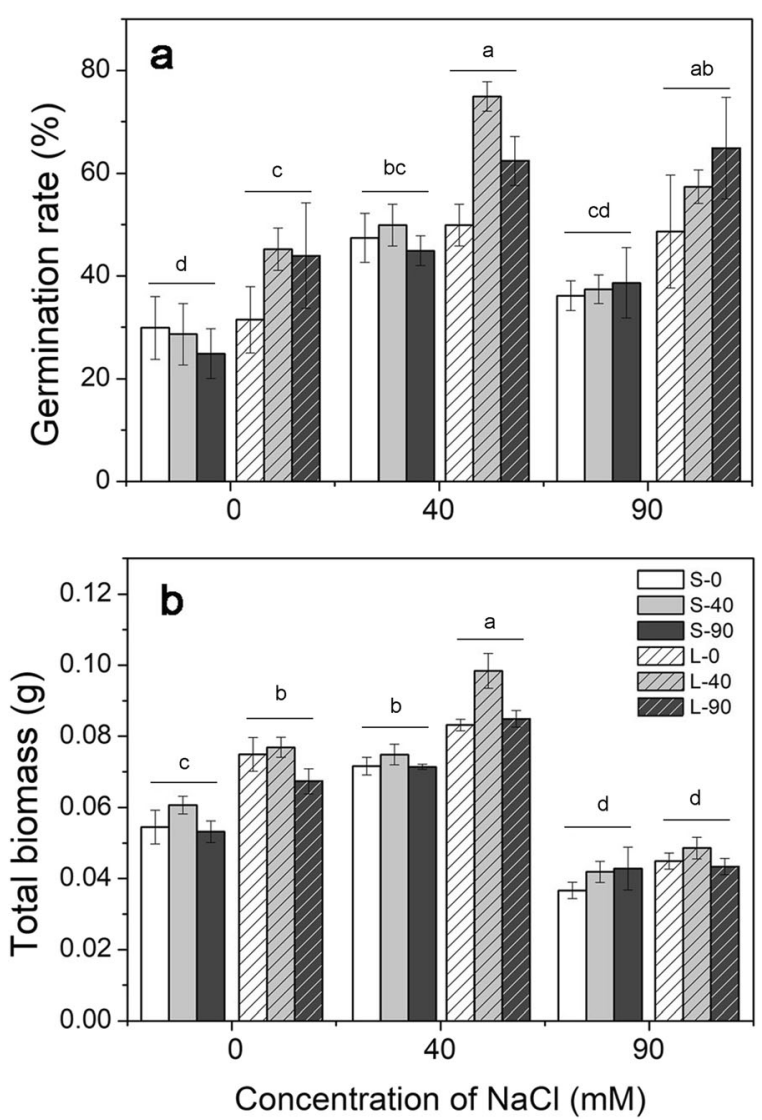

Fig. 4 Effect of origins of the soil inoculum, sterilization of the soil inoculum and contemporary soil salinities on seed germination (a) and total biomass of saplings (b) of Hibiscus hamabo. S-0, S40 and S-90 indicate sterilized soil inoculum collected from salinities of 0,40 and $90 \mathrm{mM} \mathrm{NaCl}$, respectively. L-0, L-40 and L-90 indicate live soil inocula collected from salinities of 0,40 and $90 \mathrm{mM} \mathrm{NaCl}$, respectively. Hatched bars indicate the treatments with live inoculum, and the open bars indicate the treatments with sterilized inoculum. Different lowercase letters above the bars indicate significant differences $(p<0.05)$

with the idea that some microbial OTUs from the nonsaline source soil, used as initial substrate, were sorted out with increasing salinity or became less abundant. Furthermore, the higher AMF colonization rate that we observed in the roots of $H$. hamabo at $90 \mathrm{mM} \mathrm{NaCl}$ indicates that salinity may, at least for a certain time, strengthen AMF-plant mutualisms.

Previous studies have shown that microbes play an important role in salt-stress alleviation in plants (Sheng et al. 2008; Evelin et al. 2009; Bothe 2012; Dodd and Perez-Alfocea 2012). We found that with live instead of sterilized soil inoculum, and with instead of without root-segment inoculum, $H$. hamabo plants performed better. For germination, these beneficial effects of microbes were equally pronounced at all three experimental salinity levels. The positive effect of the microbes on germination may indicate that the microbes help to soften the hard seed coat, which is a prerequisite for germination of H. hamabo. For biomass production, in contrast to germination, the beneficial effects of microbes were reduced at the highest salinity level (90 $\mathrm{mM} \mathrm{NaCl})$. Our findings suggest that the microbial communities contained overall more beneficial than pathogenic microbes for $H$. hamabo, and that these benefits did not increase with salinity. In other words, while the microbes promoted plant performance at each of the different salinity levels, they did not increase salt tolerance per se.

While the presence of microbes improved plant performance overall, we found evidence that this effect tended to be stronger with inocula originating from a similar salinity level. This was particularly the case for the intermediate salinity level of $40 \mathrm{mM} \mathrm{NaCl}$, where plants of $H$. hamabo produced most biomass when the soil or root-segment inoculum originated from the same salinity level. In the non-saline treatment of $0 \mathrm{mM} \mathrm{NaCl}$, plants also performed better when the soil or rootsegment inoculum originated from either 0 or $40 \mathrm{mM}$ $\mathrm{NaCl}$ than when it came from $90 \mathrm{mM} \mathrm{NaCl}$. At a salinity level of $90 \mathrm{mM} \mathrm{NaCl}$, however, the origin of the inoculum did not matter. Possibly, an excess salinity of the soil suppresses the facilitative effect of soil microbes on plants (Rath and Rousk 2015; Elhindi et al. 2016).

Table 2 Results of two-way ANOVAs testing the main effects and interactions of salt concentration (SC) and root-inoculum addition (RA) on total biomass of Hibiscus hamabo

\begin{tabular}{lllll}
\hline & Factors & d.f. & $F$ value & $p$ value \\
\hline Total biomass & Salt concentration (SC) & 2 & 151.782 & $<0.001 *$ \\
& Root-inoculum addition (RA) & 1 & 72.295 & $<0.001 *$ \\
& SC $\times$ RA & 2 & 8.400 & $<0.001 *$ \\
\hline
\end{tabular}




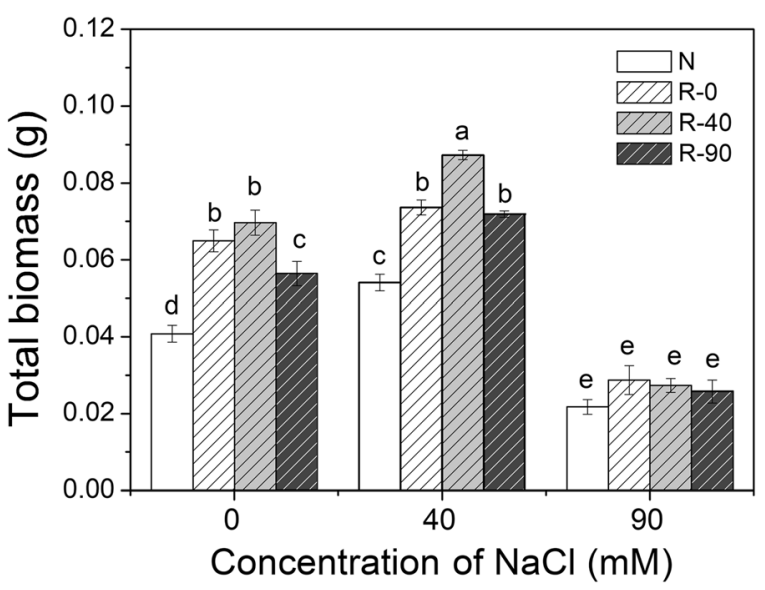

Fig. 5 Effect of addition and origin of the root-segment inoculum, and contemporary soil salinities on total biomass of saplings of Hibiscus hamabo. R-0, R-40 and R-90 indicate root-segment inoculum from salinities of 0,40 and $90 \mathrm{mM} \mathrm{NaCl}$, respectively. $\mathrm{N}$ indicates the control treatment without root-segment inoculum. Hatched bars indicate the treatments with live inoculum, and the open bars indicate the control treatment without root-segment inoculum $(\mathrm{N})$. Different letters above the bars indicate significant differences $(P<0.05)$

Potentially, the latter would not have been the case if we would have used soil from a saline field site as initial substrate, as such soil would have contained microbes adapted to high salinity. So, the local microbial communities did not promote growth of $H$. hamabo at each salinity level. However, when it did, the result was in line with the prediction of the 'habitat-adapted symbiosis' hypothesis (Rodriguez et al. 2008), which poses that the interactions between plants and microbes are more beneficial when historical and current environmental conditions match.

To the best of our knowledge, few other studies have tested whether local microbes benefit the local plants. Sedlacek et al. (2014) collected seeds of the alpine dwarfshrub Salix herbacea in different microhabitats and transplanted them into substrates inoculated with soils from the same or different microhabitats. However, that study did not reveal evidence for a home advantage.
On the other hand, Lau and Lennon (2012) grew plants of the annual herb Brassica rapa for three generations under wet and dry soil conditions, and then reciprocally transplanted the offspring between the wet and dry soil conditions. Importantly, they combined this in a factorial design with inoculation of microbes from the wet or dry soil condition. Although they found no evidence for genetic local adaptation of the $B$. rapa lines after three generations of growth in the different soil-moisture environments, they found a pattern consistent with local adaptation when the soil conditions of the contemporary test environment matched the historical soil conditions the microbial inoculum came from. Our results on H. hamabo thus show that such beneficial effects of local soil microbes may have already assembled after growing the plants for only 1 month in the specific treatments.

There can be multiple reasons for the beneficial effects on plant performance of microbial communities originating from a salinity condition that matches the contemporary salinity. Possibly, each salinity level selects those bulk-soil microbes that best function at the specific salinity, and thereby have the highest microbial ecosystem functions, such as nutrient cycling, which then positively affect plant growth. Another, non-exclusive, reason could be that the salinity level selects specifically the rhizosphere or endophytic microbes that have the strongest mutualistic interactions with the plants at the specific salinity. Evidence that soil microbes closely associated with the roots of H. hamabo (both endosphere and rhizosphere microbes) are important is provided by the fact that when we used a rootsegment inoculum, we found almost the same results as when we used a rhizsophere inoculum. Moreover, we found that root colonization of $H$. hamabo by arbuscular mycorrhizal fungi (AMF) strongly increased with salinity (Fig. 3). AMF has been shown to mediate plant physiological processes, especially nutrient acquisition, but also plant tolerance to salt stress (Evelin et al. 2009; Bothe 2012; Hashem et al. 2016; Enebe and Babalola

Table 3 Results of two-way ANOVAs testing the main effects and interactions of salt concentration (SC) and root-inoculum origin (RO) for the subset of pots with root-inoculum addition on seed germination rate and total biomass of Hibiscus hamabo

\begin{tabular}{lllll}
\hline & Factors & d.f. & $F$ value & $p$ value \\
\hline Total biomass & Salt concentration (SC) & 2 & 281.552 & $<0.001^{*}$ \\
& Root-inoculum origin (RO) & 2 & 11.078 & $<0.001^{*}$ \\
& SC $\times$ RO & 4 & 3.495 & $0.012^{*}$ \\
\hline
\end{tabular}


2018). Therefore, we conclude that it is likely that changes in the root associated AMF community of H. hamabo play an important role in the plant's response to salinity.

The finding that salinity-induced changes in soil microbial communities benefit plant growth is not only of basic interest, but also of applied interest because it could improve more efficient use and amelioration of saline soils ( $\mathrm{Li}$ et al. 2012). Although the changes in microbial communities and the benefits that they had for $H$. hamabo emerged relatively rapidly in our study, it is likely that these changes and effects would be even stronger when the microbial communities had experienced saline soils for a longer time. If that is the case, inoculation of soils that have become saline recently with microbes from soils that have been saline for a longer time could promote plant growth and ecosystem services. Such benefits would be largest if these soil microbes are not plant species specific, so that e.g. soil inoculums from H. hamabo populations would also benefit other plant species. Such a species non-specific effect was recently shown for rice seedlings that grew better on saline soil inoculated with endophytes collected from a high-salinity population of Phragmites australis than with endophytes from a low-salinity population of $P$. australis (Soares et al. 2016).

As H. hamabo is an endangered species (Zhou et al. 2013), planting it in degraded soils that suffer from salinization may contribute to its preservation. Inoculation of saline soils with microbes that promote germination and growth of H. hamabo could then increase the success rate of population establishment. This would be most feasible if the beneficial microbiome is culturable. We here showed that by experimentally exposing plants of H. hamabo and soil microbes to different salinity levels, one can create such a beneficial microbial community. In the long-term, however, also pathogenic microorganisms may accumulate and cause negative effects on H. hamabo. Therefore, it would be to useful isolate and culture the beneficial microbial taxa. For example, Baltruschat et al. (2008) showed that some culturable taxa like Piriformospora indica can promote growth of barley under salinity. Future works should thus focus on isolating such microbes for H. hamabo. In conclusion, our study shows that $H$. hamabo is tolerant to intermediate salinity levels, and that this tolerance is at least partly promoted by local rhizosphere microbes. This offers great potential to improve plant production in saline environments.
Acknowledgments This study was funded by Taizhou Afforestation Project [2015[3]], and Project entrusted by Taizhou Forest Bureau [H2015-122].

\section{References}

Al-Karaki GN (2006) Nursery inoculation of tomato with arbuscular mycorrhizal fungi and subsequent performance under irrigation with saline water. Sci Hortic 109:1-7. https://doi.org/10.1016/j.scienta.2006.02.019

Andronov EE, Petrova SN, Pinaev AG, Pershina EV, Rakhimgalieva SZ, Akhmedenov KM, Gorobets AV, Sergaliev NK (2012) Analysis of the structure of microbial community in soils with different degrees of salinization using T-RFLP and real-time PCR techniques. Eurasian Soil Sci 45: 147-156. https://doi.org/10.1134/s1064229312020044

Aroca R, Ruiz-Lozano JM, Zamarreno AM, Paz JA, Garcia-Mina JM, Pozo MJ, Lopez-Raez JA (2013) Arbuscular mycorrhizal symbiosis influences strigolactone production under salinity and alleviates salt stress in lettuce plants. J Plant Physiol 170:47-55. https://doi.org/10.1016/j.jplph.2012.08.020

Baltruschat H, Fodor J, Harrach BD, Niemczyk E, Barna B, Gullner G, Janeczko A, Kogel KH, Schafer P, Schwarczinger I, Zuccaro A, Skoczowski A (2008) Salt tolerance of barley induced by the root endophyte Piriformospora indica is associated with a strong increase in antioxidants. New Phytol 180:501-510. https://doi. org/10.1111/j.1469-8137.2008.02583.x

Bloom AJ, Chapin FS, Mooney HA (1985) Resource limitation in plants-an economic analogy. Annu. Rev Ecol Systemat 16:363392. https://doi.org/10.1146/annurev.es.16.110185.002051

Bossdorf O, Richards CL, Pigliucci M (2008) Epigenetics for ecologists. Ecol Lett 11:106-115. https://doi.org/10.1111/j.14610248.2007.01130.x

Bothe H (2012) Arbuscular mycorrhiza and salt tolerance of plants. Symbiosis 58:7-16. https://doi.org/10.1007/s13199012-0196-9

Buee M, Reich M, Murat C, Morin E, Nilsson RH, Uroz S, Martin F (2009) 454 pyrosequencing analyses of forest soils reveal an unexpectedly high fungal diversity. New Phytol 184:449456. https://doi.org/10.1111/j.1469-8137.2009.03003.x

Caporaso JG, Kuczynski J, Stombaugh J, Bittinger K, Bushman FD, Costello EK et al (2010) QIIME allows analysis of highthroughputcommunity sequencing data. Nat Methods 7:335336. https://doi.org/10.1038/nmeth.f.303

Dodd IC, Perez-Alfocea F (2012) Microbial amelioration of crop salinity stress. J Exp Bot 63:3415-3428. https://doi. org/10.1093/jxb/ers033

Edgar RC (2013) UPARSE: highly accurate OTU sequences from microbialamplicon reads. Nat Methods 10:996-998. https://doi.org/10.1038/nmeth.2604

Elhindi K, El Din AS, Abdel-Salam E, Elgorban A (2016) Amelioration of salinity stress in different basil (Ocimum basilicum L.) varieties by vesicular-arbuscular mycorrhizal fungi. Acta Agr Scand B-S P 66:583-592. https://doi. org/10.1080/09064710.2016.1204467 
Enebe MC, Babalola OO (2018) The influence of plant growth-promoting rhizobacteria in plant tolerance to abiotic stress: a survival strategy. Appl Microbiol Biot 102:7821-7835. https://doi.org/10.1007/s00253018-9214-Z

Evelin H, Kapoor R, Giri B (2009) Arbuscular mycorrhizal fungi in alleviation of salt stress: a review. Ann Bot 104:12631280. https://doi.org/10.1093/aob/mcp251

Giovannetti M, Mosse B (1980) An evaluation of techniques for measuring vesicular arbuscular mycorrhizal infection in roots. New Phytol 84:489-500. https://doi.org/10.1111/j.14698137.1980.tb04556.x

Giri B, Kapoor R, Mukerji KG (2003) Influence of arbuscular mycorrhizal fungi and salinity on growth, biomass, and mineral nutrition of Acacia auriculiformis. Biol Fert Soils 38: 170-175. https://doi.org/10.1007/s00374-003-0636-z

Giri B, Kapoor R, Mukerji KG (2007) Improved tolerance of Acacia nilotica to salt stress by arbuscular mycorrhiza, Glomus fasciculatum may be partly related to elevated K/ $\mathrm{Na}$ ratios in root and shoot tissues. Microb Ecol 54:753-760. https://doi.org/10.1007/s00248-007-9239-9

Göransson H, Welc M, Bünemann EK, Christl I, Venterink HO (2016) Nitrogen and phosphorus availability at early stages of soil development in the Damma glacier forefield, Switzerland; implications for establishment of $\mathrm{N}_{2}$-fixing plants. Plant Soil 404:251-261. https://doi.org/10.1007/s11104-016-2821-5

Hashem A, Abd Allah EF, Alqarawi AA, Ai-Huqail AA, Wirth S, Egamberdieva D (2016) The interaction between arbuscular mycorrhizal fungi and endophytic bacteria enhances plant growth of Acacia gerrardii under salt stress. Front Microbiol 7:1089. https://doi. org/10.3389/fmicb.2016.01089

Jahromi F, Aroca R, Porcel R, Ruiz-Lozano JM (2008) Influence of salinity on the in vitro development of Glomus intraradices and on the in vivo physiological and molecular responses of mycorrhizal lettuce plants. Microb Ecol 55:4553. https://doi.org/10.1007/s00248-007-9249-7

Juniper S, Abbott LK (2006) Soil salinity delays germination and limits growth of hyphae from propagules of arbuscular mycorrhizal fungi. Mycorrhiza 16:371-379. https://doi. org/10.1007/s00572-006-0046-9

Kawecki TJ, Ebert D (2004) Conceptual issues in local adaptation. Ecol Lett 7:1225-1241. https://doi.org/10.1111/j.14610248.2004.00684.x

Lastochkina O, Pusenkova L, Yuldashev R, Babaev M, Garipova S, Blagova D, Khairullin R, Aliniaeifard S (2017) Effects of Bacillus subtilis on some physiological and biochemical parameters of Triticum aestivum L. (wheat) under salinity. Plant Physiol Bioch 121:80-88. https://doi.org/10.1016/j. plaphy.2017.10.020

Lau JA, Lennon JT (2011) Evolutionary ecology of plant-microbe interactions: soil microbial structure alters selection on plant traits. New Phytol 192:215-224. https://doi.org/10.1111/j.14698137.2011.03790.x

Lau JA, Lennon JT (2012) Rapid responses of soil microorganisms improve plant fitness in novel environments. Proc Natl Acad Sci 109:14058-14062. https://doi.org/10.1073/pnas.1202319109

Li HY (2008) Three dimensional variability and visualization of soil electrical conductivity in coastal saline land. $\mathrm{PhD}$ Thesis. Zhejiang University
Li JM, Liao JJ, Guan M, Wang EF, Zhang J (2012) Salt tolerance of Hibiscus hamabo seedlings: a candidate halophyte for reclamation areas. Acta Physiol Plant 34:1747-1755. https://doi.org/10.1007/s11738-012-0971-5

Li HS, Lei P, Pang X, Li S, Xu H, Xu ZQ, Feng XH (2017) Enhanced tolerance to salt stress in canola (Brassica napus L.) seedlings inoculated with the halotolerant Enterobacter cloacae HSNJ4. Appl Soil Ecol 119:26-34. https://doi. org/10.1016/j.apsoil.2017.05.033

Lin X, Feng Y, Zhang H, Chen R, Wang J, Zhang J, Chu H (2012) Long-term balanced fertilization decreases arbuscular mycorrhizal fungal diversity inan arable soil in North China revealed by 454 pyrosequencing. Environ SciTechnol 46: 5764-5771. https://doi.org/10.1021/es3001695

Mohamed DJ, Martiny JBH (2011) Patterns of fungal diversity and composition along a salinity gradient. Isme J 5:379-388. https://doi.org/10.1038/ismej.2010.137

Nguyen NH, Song ZW, Bates ST, Branco S, Tedersoo L, Menke J, Schilling JS, Kennedy PG (2016) FUNGuild: an open annotation tool for parsing fungal community datasets by ecological guild. Fungal Ecol 20:241-248. https://doi.org/10.1016/j. funeco.2015.06.006

Nicotra AB, Atkin OK, Bonser SP, Davidson AM, Finnegan EJ, Mathesius U, Poot P, Purugganan MD, Richards CL, Valladares F, van Kleunen M (2010) Plant phenotypic plasticity in a changing climate. Trends Plant Sci 15:684-692. https://doi.org/10.1016/j.tplants.2010.09.008

Oduor AMO, Leimu R, van Kleunen M (2016) Invasive plant species are locally adapted just as frequently and at least as strongly as native plant species. J Ecol 104:957-968. https://doi.org/10.1111/13652745.12578

Oksanen J, Blanchet FG, Kindt R, Legendre P, Minchin P (2011) The vegan package: community ecology package. R package version 2.0-2. Available: http://www.R-project.org. Accessed on 3.2.2015

Pankhurst CE, Yu S, Hawke BG, Harch BD (2001) Capacity of fatty acid profiles and substrate utilization patterns to describe differences in soil microbial communities associated with increased salinity or alkalinity at three locations in South Australia. Biol Fert Soils 33:204-217. https://doi. org/10.1007/s003740000309

Patel S, Jinal HN, Amaresan N (2017) Isolation and characterization of drought resistance bacteria for plant growth promoting properties and their effect on chilli (Capsicum annuum) seedling under salt stress. Biocatal Agric Biotechnol 12:8589. https://doi.org/10.1016/j.bcab.2017.09.002

Porcel R, Aroca R, Ruiz-Lozano JM (2012) Salinity stress alleviation using arbuscular mycorrhizal fungi. A review. Agron Sustain Dev 32:181-200. https://doi.org/10.1007/s13593011-0029-x

R Core Team (2014) R: A language and environment for statistical computing. R Foundation for Statistical Computing, Vienna, Austria. URL http://www.R-project.org/. Accessed on 3.2.2015

Rath KM, Rousk J (2015) Salt effects on the soil microbial decomposer community and their role in organic carbon cycling: a review. Soil Biol Biochem 81:108-123. https://doi.org/10.1016/j.soilbio.2014.11.001 
Roach DA, Wulff RD (1987) Maternal effects in plants. Annu Rev Ecol Systemat 18:209-235. https://doi.org/10.1146/annurev. ecolsys.18.1.209

Rodriguez RJ, Henson J, Van Volkenburgh E, Hoy M, Wright L, Beckwith F, Kim YO, Redman RS (2008) Stress tolerance in plants via habitat-adapted symbiosis. Isme J 2:404-416. https://doi.org/10.1038/ismej.2007.106

Ruiz-Lozano JM, Porcel R, Azcon C, Aroca R (2012) Regulation by arbuscular mycorrhizae of the integrated physiological response to salinity in plants: new challenges in physiological and molecular studies. J Exp Bot 63:4033-4044. https://doi. org/10.1093/jxb/ers126

Sardinha M, Muller T, Schmeisky H, Joergensen RG (2003) Microbial performance in soils along a salinity gradient under acidic conditions. Appl Soil Ecol 23:237-244. https://doi. org/10.1016/s0929-1393(03)00027-1

Sarkar A, Ghosh PK, Pramanik K, Mitra S, Soren T, Pandey S, Mondal MH, Maiti TK (2018) A halotolerant Enterobacter sp displaying ACC deaminase activity promotes rice seedling growth under salt stress. Res Microbiol 169:20-32. https://doi.org/10.1016/j.resmic.2017.08.005

Sedlacek JF, Bossdorf O, Cortes AJ, Wheeler JA, van Kleunen M (2014) What role do plant-soil interactions play in the habitat suitability and potential range expansion of the alpine dwarf shrub Salix herbacea? Basic Appl Ecol 15:305-315. https://doi.org/10.1016/j.baae.2014.05.006

Sheng M, Tang M, Chen H, Yang BW, Zhang FF, Huang YH (2008) Influence of arbuscular mycorrhizae on photosynthesis and water status of maize plants under salt stress. Mycorrhiza 18:287-296. https://doi.org/10.1007/s00572008-0180-7

Soares MA, Li HY, Kowalski KP, Bergen M, Torres MS, White JF (2016) Evaluation of the functional roles of fungal endophytes of Phragmites australis from high saline and low saline habitats. Biol Invasions 18:2689-2702. https://doi. org/10.1007/s10530-016-1160-z
Takahashi S, Tomita J, Nishioka K, Hisada T, Nishijima M (2014) Development of a prokaryotic universal primer for simultaneous analysis of bacteria and archaea using next-generation sequencing. PLoS One 9. https://doi.org/10.1371/journal. pone. 0105592

Tester M, Davenport R (2003) $\mathrm{Na}^{+}$tolerance and $\mathrm{Na}^{+}$ transport in higher plants. Ann Bot 91:503-527. https://doi.org/10.1093/aob/mcg058

Walsh DA, Papke RT, Doolittle WF (2005) Archaeal diversity along a soil salinity gradient prone to disturbance. Environ Microbiol 7:1655-1666. https://doi.org/10.1111/j.14622920.2005.00864.x

Wang XL (2010) Study of the mechanisms of salt tolerance in Hibiscus hamabo. Shanghai Jiaotong University, Master Thesis

Yan N, Marschner P, Cao WH, Zuo CQ, Qin W (2015) Influence of salinity and water content on soil microorganisms. Int Soil Water Conserv Res 3:316-323. https://doi.org/10.1016/j. iswer.2015.11.003

Yang H, Du G, Wang K (2008) Study on the physiological characteristics of Hibiscus hamabo under stress. J Zhejiang Forest Sci Technol 28:43-47

Yuan BC, Xu XG, Li ZZ, Gao TP, Gao M, Fan XW, Deng HM (2007) Microbial biomass and activity in alkalized magnesic soils under arid conditions. Soil Biol Biochem 39:3004 3013. https://doi.org/10.1016/j.soilbio.2007.05.034

Zhou H, Li H, Shao X, Fang C, Ye X, Wu M (2013) Physiological properties changes of Hibiscus hamabo seedlings under different salinity water logging. J Zhejiang Forest Sci Technol 33:41-45

Publisher's note Springer Nature remains neutral with regard to jurisdictional claims in published maps and institutional affiliations. 